\title{
TEACHER ROLE MODEL AND STUDENTS' PHYSICAL ACTIVITY Teacher role model and student's physical activity
}

\author{
INGRIDA SMUKA \\ Latvian Academy of Sport Education, Department of Skiing, Shooting, \\ Orienteering, Tourism and Recreation
}

\begin{abstract}
Mailing address: Ingrida Smuka, Latvian Academy of Sport Education, Department of Skiing, Shooting, Orienteering, Tourism and Recreation, 333 Brivibas Street, Riga, LV-1006, Latvia, tel.: +37 129106618, fax: +37 167543480, e-mail: ingrida.smuka@lspa.lv
\end{abstract}

\begin{abstract}
Introduction. Physical activity is an important factor in health risk prevention, which improves the quality of life, as well as promotes both physical and mental health preservation [1, 2]. Each year, the lack of physical activity causes death of 600,000 people in Europe - approximately 6\% of the total population [3]. Despite the significant number of studies that have been conducted on students' physical activity, it is also being claimed that studies on the teenage group are essential yet scarce, and the results are ambiguous [4]. This confirms the need for more such studies in order to better determine the significant factors in the promotion of students' physical activity. Material and methods. 339 students aged 11 to 19 participated in the collection of data base: 147 boys and 192 girls. Average age of participants was: 14.6 years. 75 students aged 14-19 years (33 girls and 42 boys) were involved in the pedagogical experiment. The average age of the participants was 16-19 years in School 1 (11 girls and 18 boys), and 14-17 years in School 2 (19 girls and 27 boys). Average age of participants was: 16.3 years. Three sports teachers participated in the pedagogical experiment as well. During the course of the experiment, teachers developed a model of pedagogical interaction in physical education classes. At each school the experiment lasted for 14 weeks. In both schools physical education classes were held twice a week. Results. Based on factor analysis, a model of pedagogical interactions promoting physical activity of students was developed. According to the results of the physical activity habits test (inventory) we can conclude that students have experienced positive and statistically significant changes in their physical activity. The boys were considerably more active during classes where the teacher was present as a participant of physical activities. Conclusions. Teachers and students remark that the applied contents of the pedagogical interaction model have positive effects on the interaction between students and teachers and stimulate physical activity of students.
\end{abstract}

Key words: physical activity, teacher role model

\section{Introduction}

Each year, the lack of physical activity causes the death of 600,000 people in Europe (that equals approximately $6 \%$ of the total population); lack of exercise also leads to overweight or obesity of more than one million people. These are just a few facts mentioned in the World Health Organization (WHO) report on physical activity and health in the European region [3].

Physical activity is an important factor in health risk prevention that improves the quality of life, as well as promotes both physical and mental health preservation $[1,2]$. Researchers indicate that the current epidemic of physical inactivity has had a very strong influence, particularly on the teenage group, and has become a public health problem. The immobility of teenagers is high in both rich, as well as less developed countries [5].

Physical activity reduces the risk of non-communicable diseases; it also increases the social interaction and community involvement, and is beneficial to the society as a whole. Physical activity not only helps to address public health issues, but promotes the well-being of communities and environmental protection, while also contributing to future generations [6].

At the moment, the issue of the effect of physical activity on the human health has not lost its topicality and is being broadly discussed in scientific literature $[7,8,9,10]$.
Insufficient physical activity is a problem throughout the world. A WHO report says that, out of 15 EU countries, an average number of $50 \%$ of the respondents admitted that they were not engaged in any physical activities or that they were engaging in physical activities less than once a month. The lowest rates were recorded in the following countries: Bulgaria $(82 \%)$, Greece (79\%), Hungary (71\%), Romania (69\%), Italy (67\%), Poland (66\%) and Latvia (65\%) [11].

Physical activity is a significant precondition to maintain and improve health at every age; however, it is especially important for children.

In an article published in the Preventive Medicine magazine, it was suggested by C.A Loucaides, R. Jago, and I. Charalambous that students' physical activity at school could be increased by offering additional physical activities in the school yard, during breaks in between classes. A study, conducted in Cyprus, showed that allocating a special place within the school territory for students' physical activities during breaks encouraged students to engage in physical activities [12].

S. Racette, W. Cade and L. Becman suggest changing the school curriculum by increasing the amount of time set aside for physical activities and high intensity exercises, providing equipment necessary for physical activities, training teachers on how to implement the new programs, and involving parents in the implication of the program. They also state that munici- 
palities and mass media should be involved in the implementation of physical activity policy [13].

As an incidental observation, it was also found in this study, that it was enough for the teacher just to be present at the place, where physical activities occurred, to have a positive impact and increase students' activity; this is particularly the case with the boys, whose activity increased five times, as opposed to the girls, whose activity increased four times. It is acknowledged that the increased activity of the boys was related to the desire to demonstrate their skills to the teacher.

Despite the significant number of studies that have been conducted on students' physical activity, it is also being claimed that studies on the teenage group were essential, yet scarce, and the results were ambiguous [4]. This confirms the need for more such studies in order to better determine the significant factors in the promotion of students' physical activity.

The teacher - student interaction is a key aspect in the success of the learning process; successful interaction requires the teacher to have good communication skills, knowledge of psychology, ability to model relationships and predict the possible results, be a step ahead of the students. Such cooperation is a sign of the human learning process. Interaction between teachers and students on equal terms appears to enrich the students. In such cooperation, the teacher is the positive role model and thus, can motivate the students toward positive changes.

In order to successfully manage the pedagogical process, the teacher must have the knowledge and understanding of the structure and dynamics, and the main regularities. Teaching skills are very important in the pedagogical process. A number of authors have identified several groups of teaching skills: didactic, expressive, perceptive, organizational, suggestive and scientific or academic research oriented. Alternatively they could also be divided into the following groups: personality related, didactic and organizationally communicative.

A teacher is a role model in the daily collective work. A role model is something special in daily activities; as he or she serves as a demonstrative approval, and as a specification of ideas, features, and standards of behaviour that we teach or would like to teach to our students [14].

Several researchers have studied interaction in the pedagogical process. They note that the pedagogical interaction includes not only pedagogical activities planned by the teacher, but also students' self-developing reaction and action that can also vary according to individual characteristics. Consequently, both the teacher and the student are active participants of the pedagogical process and have an influence on one another. In the course of this study a number of pedagogical models based on scientific findings were gathered by $\mathrm{D}$. Liegeniece, were used $[15,16]$.

According to the Behaviourist model, the most active part is the teacher who prepares a good course of study, a lesson, or a lecture and teaches according to the following formula: stimulus $\rightarrow$ reaction. Learning based on this model focuses on the teacher, who "has" all the information. The teacher's role is to "pass" the knowledge to the student. The knowledge gained by the student can be objectively evaluated and measured in terms of "knows" or "does not know".

The model based on the cognitive theories respects the formation of students' comprehension. Educators and psychologists who use this philosophy characterize learning as a complex process that includes problem-solving ability, intuition, imagination and perception. In this model, the internal structure of thought is of a greater importance than the external stimuli and observations. The foundations of this philosophy were developed by Piaget $[17,15,16]$.

The main point of the humanistic interaction model is to help students towards self-actualisation. This model respects the development of a student's motifs and the involvement of the student in the teaching process that is significant to him/her. This model is based on Maslow's [18] and Vygotsky's [19] findings that intend to help students towards self-actualization.

The experiential learning model, developed by Kolb, is based on a simple description of how experience is transformed into concepts that can be used to lead the choice of new experiences. Kolb believes that experienmce forms the basis for observation and reflection, during which notions or concepts are derived and tested later on. During this testing, a new experience is created, and a new cycle begins [15, 16].

Another model developed by Kolb was also examined. It is a teaching model based on experience. This model is founded upon a simple description of how experience is transformed into concepts that can be used to lead the choice of new experiences [20].

According to information found in the literature, there is also an optimal pedagogical model that could be applied by teachers. The main idea of this model is that teachers have to work as a united "pedagogical team", so that by teaching a particular group of students they are interacting not only with this particular group, but also among themselves [21].

The Spectrum range of learning styles was also analysed. The theory of these teaching styles was developed by Mosston (1950 and 1960). The structure of the Spectrum is based on two sets of styles: the first contains a set of styles that can be used for replication, while the second one encourages new discoveries and creativity. The Spectrum theory includes eleven teaching styles. Each style is characterized by its own decision-making type and title, which is represented by a particular letter [22, 23].

When analysing contemporary pedagogical principles, we can see that the modern pedagogy is often related to the humane pedagogy; A. Spona states, however, that "We live in a situation in which the pedagogical practice is still largely dominated by the basic ideas of the Soviet pedagogy." Nowadays, a greater responsibility is required from teachers. More emphasis is placed on subjects that help to prepare students for information and technologies in the labour market and because of this, moral values are not a priority. Yet we must take into account that a teacher's position in the organization of the pedagogical process is one of the most important means of education, and equal participation is the basis for productive and creative teacher-student cooperation.

Considering the previous recorded facts, it was decided to pursue this study, which could help to better understand the factors that contribute to students' physical activity.

\section{Material and methods}

75 students aged 14-19 years (33 girls and 42 boys) were involved in the pedagogical experiment. Average age of participants was 16.3 years. Three sports teachers participated in the pedagogical experiment. The experiment was held at two schools: Kandava boarding school "Dzîves prieks" (School 1) and Natâlija Draudziňa Gymnasium (School 2).

During the course of the experiment the teachers used the existing model of pedagogical interaction in the physical education classes. At each school, the experiment lasted for 14 weeks. Components of the pedagogical interaction model (Fig.1):

- Teacher: One of the key components of pedagogical interactions. The teacher, filling the contents of the model with his or her actions, stimulates the pupils'interest in physical activity and causes the pupils to be involved in physical activities on a regular basis. Also, by performing the aforementioned actions, the emotional background during the classes is being 
increased, which in turn stimulates the pupis to attend physical education classes and be physically active in their daily lives. A. Bandura stresses the importance of external stimuli in the formation of human behaviourhowever, he does not see these stimuli as the only means. A much more important role is being played by earning via observing. onsidering what has been stated before, we can assume that the teacher' actions and the style of these actions may influence change in pupils'behaviour, and the teacher' actions act as a positive example for the pupils.

- Microenvironments is the environment of a group of students, which the teacher can influence and affect the students' attitudes. The teacher creates a positive atmosphere during physical education class by applying a democratic style of guidance and by treating pupils as equal. The microenvironment of the school and class has influence on the pupils'willingness to get involved in physical education classes. It promotes the formation of positive emotions during physical activities, thus developing the pupil' physical activity in general -not only during classes, but also in daily life.

- Physical activity. This is the main component in the development process of the habit of physical activity. This component, according to our model, is being influenced by the teacher performing the actions described above. This component has been included in the model based $n$ the results of factor and correlation analysis, which indicated its significance in the process of habit development.

\section{Results}

According to the data collected during the field study, 61 centres providing services related to equestrian tourism function in the Lublin Region (Fig. 1). This constitutes only $5.5 \%$ of centres of the type in Poland [14]. The highest number of centres offering equestrian tourism services function in the Zamość - 10 (Roztocze) and Bielsko Biała poviats - 9 (Polesie). The lowest number with only 1 centre was recorded in the Opole and Parczew poviats (Fig. 2). No centres are located in the Kraśnik, Lubartów and Łuków poviats and in the urban poviats of Biała Podlaska, Chełm and Zamość.

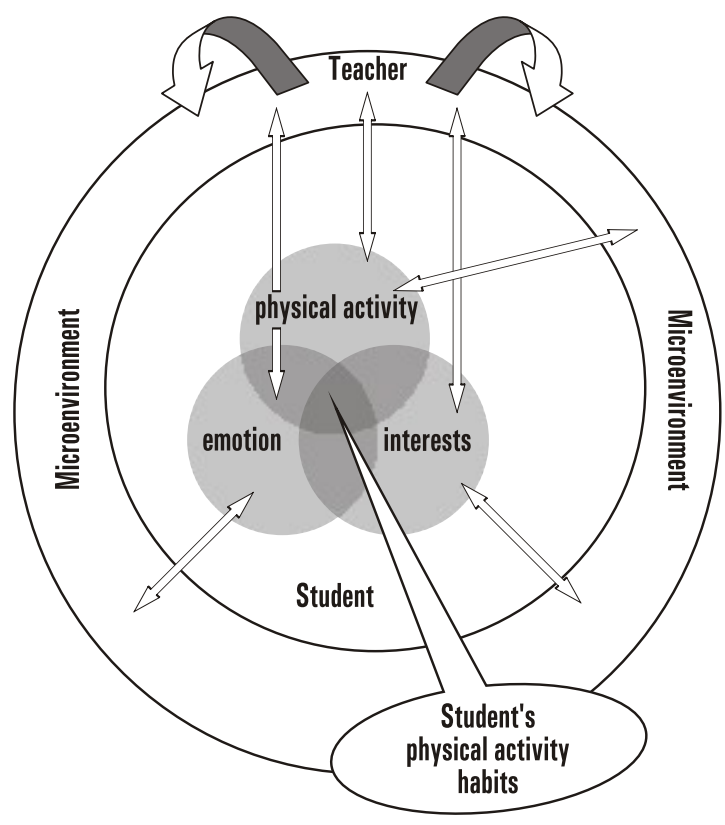

Figure 1. Pedagogical interaction model promoting students' physical activity habits
- Emotions. This factor has been included in the model based on the results of factor and correlation analysis, which indicated its significance in the process of habit development. In the correlation matrix, we can see its influence on the physical activity and the motional state. Emotions play a key role in a person' motivation to act in a certain way. The teacher creates a positive atmosphere in the classby applying a democratic style of actions, he or she can advance the pupil' positive emotions caused by performing physical activities. As the relations with the pupils improve, the level of trust increases, and, as a result, the teacher can influence the emotional background during the classes with his or her involvement.

- Interests are included into the model along with physical activity and emotions, based upon the results of factor and correlation analysis. The teacher can develop a pupil' interest in physical activities by his or her actions and organization of the class, for example, by organizing sport-related quizzes or extracurricular activities, as well as providing information on the importance of physical activities in the daily lie. The main goal of developing the model is to promote the habit of physical activity.

Three main requirements for the implementation of the pedagogical interaction model are described in the Subchapter (Fig. 2):

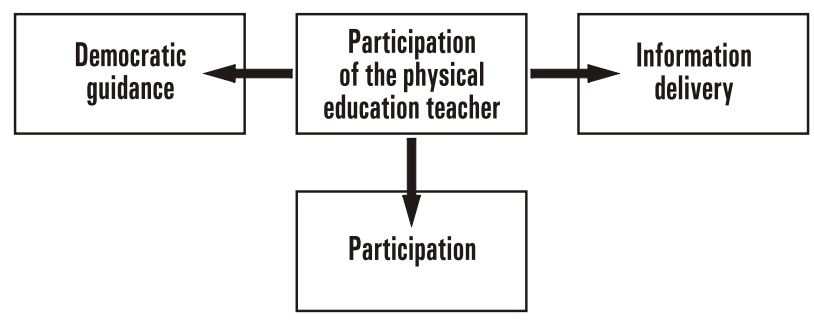

Figure 2. The action of a physical education teacher in the implementation of the pedagogical interaction model

In this study the following methods were used:

- Survey methodology (survey): Collection of basic data regarding the students'physical activities.

- Semi-structured interview: To find out the students'and the teachers'opinions on the application of the pedagogical interaction model in practice.

- Pedometry, recording and analysis of steps run by students during sports classes.

- Analysis of documentary material, i.e. protocols.

- Pedagogical experiment (at a comprehensive school in Riga and a boarding school in Kandava, participating students aged 14 to 19 and physical educators).

- Statistical data analysis methods.

\section{Results}

Before the experiment, the ANOVA test was performed on the groups of both schools. The results, could not be analysed by combining the both groups, hence they were analysed separately. Upon reviewing the data, we can say that, after the approbation of the pedagogical interaction model, there were changes in the pupils' physical activities.

Statistically significant changes in figures depicting the frequency of physical activity occurred in the case of School 1 after the experiment (Fig. 3).

The following denotations were used in this chart:

1 - "less than once a month"; 2 -"once a month"; 3 - "2-3 times 
a month"; 4 - "once a weak"; 5 - "2-3 times a weak"; 6 - "more than 3 times a weak" ; 7 - "every day".

The number of pupils performing physical activities on a daily basis increased by $18 \%$; the number of pupils performing physical activities more than 3 times a week increased by $24 \%$; 2-3 times a week - by $43 \%$; there were no changes in the group of pupils performing physical activities once a week or less frequently. The biggest increase occurred in the "2-3 times a week" group. The changes were statistically significant, $\mathrm{p}<0.05$.

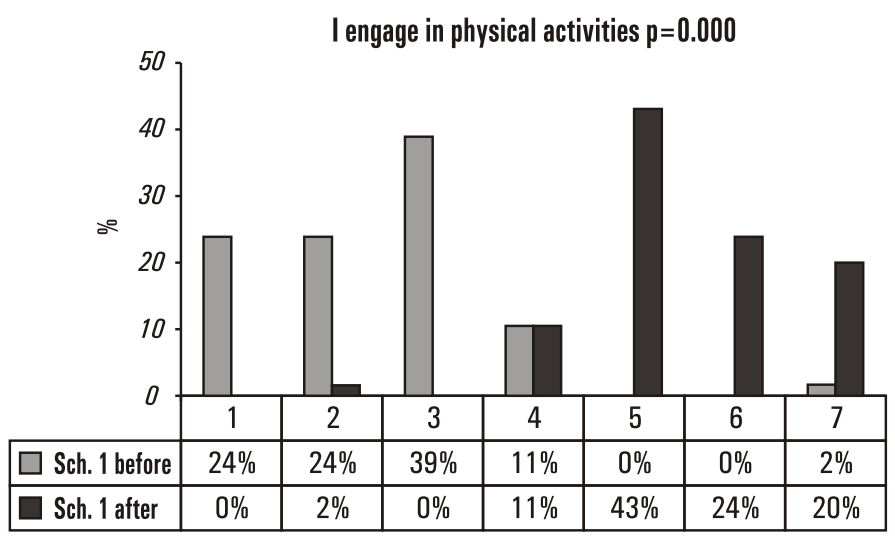

Figure 3. The frequency of physical activity performance before and after the experiment

Statistically significant changes in the frequency of physical activity (Fig. 4) also occurred at School 2. After the experiment, the number of students performing activities on a daily basis increased by $12 \%$; the number of pupils performing physical activities more than 3 times a week increased by 11\%, 2-3 times a week - by $15 \%$, and there were no changes in the group of pupils performing physical activities once a week or less. The most significant increase occurred in the "2-3 times a week" group. The changes were statistically significant, $\mathrm{p}<0.05$.

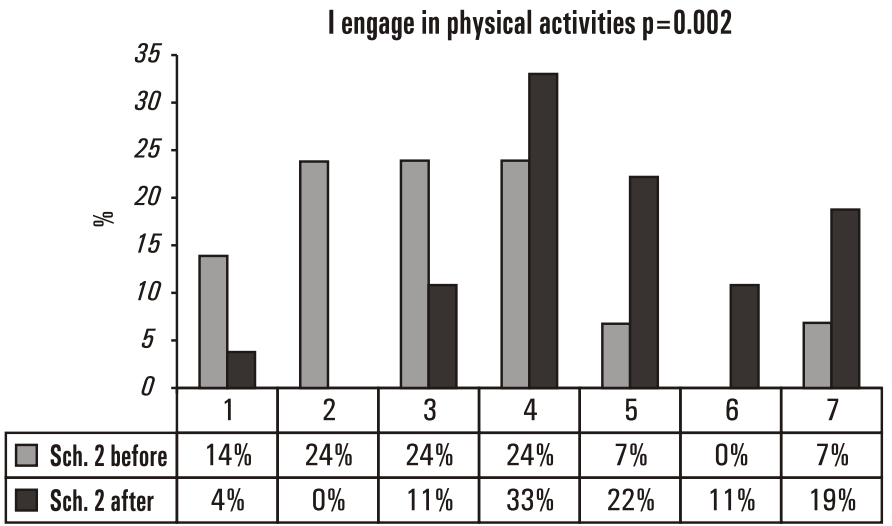

Figure 4. The frequency of physical activity performance before and after the experiment
After introducing the interaction model, individually performed physical activities increased in School 1 (Fig. 5).

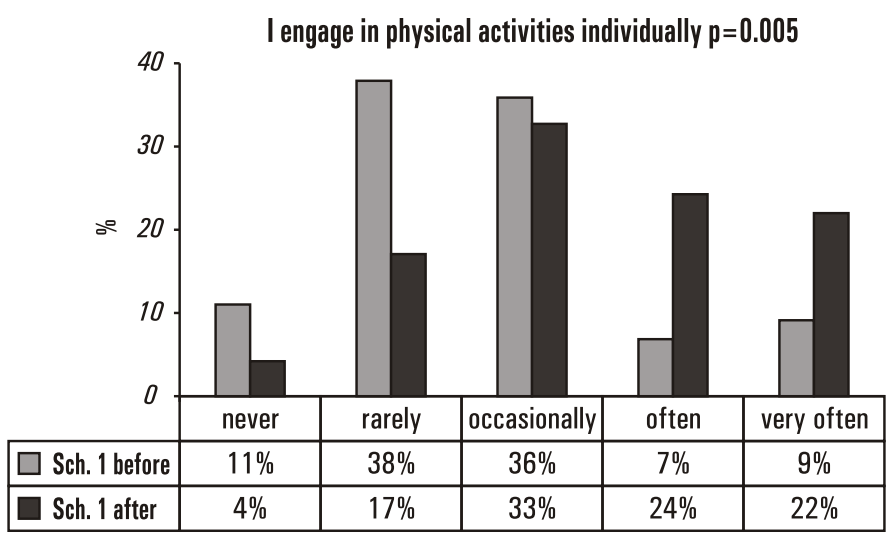

Figure 5. Individually performed physical activities before and after the experiment

The number of students "very often" engaging in individual physical activities increased by $13 \%$, while the number of those "often" engaging in physical activities - increased by $17 \%$. The changes were statistically significant, $\mathrm{p}<0.05$.

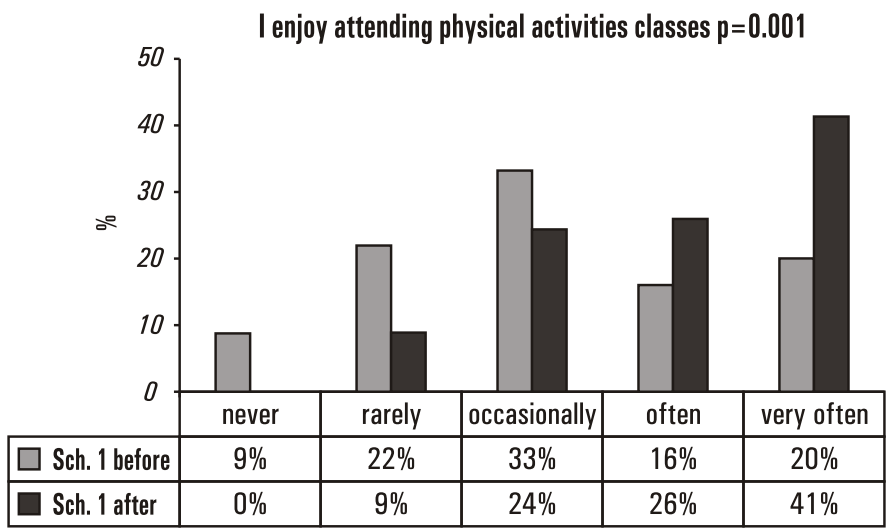

Figure 6. Physical education class attendance before and after the experiment

After the introduction of the interaction model into PE classes at School 1 (Fig. 6), the number of students who "very often" eagerly attended the classes increased by $21 \%$, and the number of students who "often" eagerly attend the classes was $10 \%$ higher than beforehand. The number of students who "occasionally" or "rarely" enjoyed physical education classes also proportionally decreased. The changes were statistically significant, $\mathrm{p}<0.05$.

At School 2, statistically significant changes occurred to a lesser extent. It could be explained by the smaller number of classes at School 2, in which the teacher applied the pedagogical interaction model, as well as the amount of time that the teacher spent with the students after classes or extracurricular activities, and the teacher's comprehension of the use of the pedagogical interaction model.

In this subchapter, the results of pedometric testing were also reviewed. The data were obtained using readings of a pedometer (steps per hour). According to T-test results (pairs of classes), the increase in the results of girls' classes were not sta- 
tistically significant, because some of the indicators were below sig.0.05 (in seven pairs out of $24, \mathrm{p}<0.05$ ); the situation amongst the boys was slightly better, in 16 pairs out of 24 , sig. $<0.05$. This indicates that the teacher's involvement in the class stimulated the boys' physical activity more than it was in the case of the girls'.

After the experiment, the participants were invited to interviews, to express their opinions about the model and the benefits and drawbacks they had noticed. In the interview analysis, the benefits and the drawbacks of the model were reviewed as seen by the participants of the experiments and the teachers. The interviews were partially structured.

The teachers evaluated the contents of the model as followed: "I believe that it (the content of the model) is very good, the students very much enjoyed attending PE classes...". The contents of the model stimulated physical activity amongst the students who were physically inactive before: "... their activity during these six months was very good in general, and it was the least active group that attended the extracurricular activities the most...". In the work with the girls, the teacher evaluated the model's contents as follows: "... it is positive. The students have a different attitude towards what they are supposed to do, because, when the teacher is also doing the same, they appear to be more interested."

When asked about the efficiency of the model's contents and their influence on students, the teacher at Kandava Boarding school said: "Young people trust the grownups". "They perceive the teacher as one of them, and see that he doesn't force them to do impossible things. This brings the teacher and pupil closer together, and makes it easier to work". It was mentioned that the model made teachers and students equal: “...some boundaries are broken between the educator and the student. I think, there is actually some equality."

Asked if the relationship between the teacher and pupil changed in the situation, where the teacher took part in the activities and, if it did, they responded that: "The relationship become better and friendlier". In conclusion of the interview, the students were asked if, after the experiment, they would want the educator to continue taking part in the class activities, and the answer was "Yes! Even more often!".

\section{Discussion}

Several research projects were conducted in Latvia and other countries in Europe and around the world about students' physical activity and factors that influence this type of activity. There have not been enough studies about the action of teachers during PE classes, oriented at the habit of promoting physical activity for students. Students tend to live sedentary life styles this fact was established by research studies conducted in Latvia and around the world as well.

Data provided by the Public Health Agency (PHA) of Latvia show that less than a half $(46.3 \%)$ of teenage school children in Latvia get enough physical activity. As they get older, the physical activity reduces significantly. The survey showed that a large proportion of students preferred watching television or spending time with their computers instead of engaging in physical activities in their spare time. The average number of hours spent watching TV was 4.78 hours on weekdays, but on weekends it reached 5.48 hours. On average, children spend 3.25 hours on weekdays and 3.51 hours on weekends playing games on their computer, communicating with friends, or doing their homework [4].

The results of our research showed that the actions model developed and used by the teacher encouraged the students to take up physical activity. However, the boys' physical activity was at a higher level than that of their female counterparts.
These facts are proved by the results of the research conducted by S. Racette, W. Cade, L. Becman which concludes that it is enough for the teacher just to be present at the place, where physical activities are performed to have a positive impact and increase students' physical activity; this particularly applies to boys (their activity increases 5 times), however in the case of the girls it is only 4 times. It is acknowledged that the boys' increased activity was related to the desire to demonstrate their skills to the teacher.

Considering the above recorded facts, it is necessary to conduct more research projects, looking for new techniques and methods to motivate girls to become more involved in physical activity.

\section{Conclusions}

If the contents of the purposefully developed model are to be applied to physical education classes on a regular basis, it would stimulate the pupils' overall level of physical activity.

The contents of the developed model of pedagogical interaction were applied in practice in course of this pedagogical experiment, and resulted in occurrence of positive and statistically significant changes in the level of physical activity of the pupils at the both schools involved in the experiment.

- The number of students who engage in physical activities on a daily basis increased by $18 \%$ the number of students performing physical activities more than 3 times a week increased by $24 \%$, and the number of those exercising 2-3 times a week -increased by $43 \%$.

- There was a $13 \%$ increase in the number of students performing physical activities individually very often, and a $17 \%$ increase in the number of those who often individually performed physical activities.

- The number of students who very often eagerly attended physical education classes increased by $21 \%$, while the number of students very often eagerly attending physical education classes went up by $10 \%$.

The analysis of pedometer tests indicated that:

- Without the participation of an educator in physical activities during $\mathrm{PE}$ classes, girls ran an average of $100 \%$ stepshowever, they ran an average of $110.55 \%$ steps if the teacher was involved in the activities. If we assume that with the participation of the teacher in physical activities they ran $100 \%$ steps, then without the teacher' participation they ran only $90.45 \%$. By comparing the percentages we can see that the girls were more active during classes, where the teacher was present as a participant of the physical activities. It is also proven by the correlation analysis, which shws that the correlation between data sets is medium close, which i indicated by $\mathrm{r}=0.635$ and sig.2-tailed) $=0,01$. Thus, the data obtained during the classes, where the educator actively participated in the physical activities are statistically significantly different from the data obtained during the classes, where no teacher was present.

- Without the participation of an educator in physical activities during $\mathrm{PE}$ classes, boys ran an average of $100 \%$ stepshowever, they ran an average of $140.99 \%$ steps if the teacher is involved in the activities. If we assume that with the participation of the teacher in physical activities they ran $100 \%$ steps, without the teacher' participation they only ran $70.92 \%$. We can conclude that the boys were considerably more active during classes where the teacher was present as an active participant of physical activities.

- According to the T-test results of pedometric pairs, the increase in results of all classes by both boys and girls are not statistically significant. For girls, the pedometric test results sig. $<0.05$ (in seven pairs out of 24), for boys - sig. $<0.05$ in 16 
pairs out of 24. This indicates that the involvement of teachers stimulates physical activity more in the case of boys than it is in the case of girls.

The interview results after the approbation of the developed pedagogical action model indicate that significant changes occurred in the physical activity of students, and the students' interests changed along with their level of involvement in the performance of these activities. Opinions about the use and efficiency of the model were expressed by the teachers and the students alike. The teachers, as well as the students positively evalated the model. Both, the teachers and the pupils remarked that the applied contents of the pedagogical interaction model had positive effects on the interaction between the students and the teachers, stimulated positive emotions during the performance ofphysical activities, as well as stimulated the students' physical activity itself. The only negative aspect mentioned was the physical fitness of the teachers, because not all teachers were able to perform the physical activities along with their students.

\section{Literature}

1. Alves, J., Montenegro F, Oliveira F. \& Alves R. (2005). Sports during adolescence and physical activity in the leisure time in adulthood. Revista Brasileira de Medicina do Esporte 11(5), 291-294. [in Portuguese]

2. Matias, T., Rolim M., Kretzer F., Schmoelz C., Andrade A. (2010). Adolescents well-being and physical activity. Motriz. Journal of Physical Education. UNESP 16(2), 370-378. [in Portuguese]

3. World Health Statistics. (2006, July). Public Health Mapping and GIS, Communicable Diseases, World Health Organization. Retrieved July 5, 2010, from the World Wide Web: http:// books.google.com/books?id=C8rkX-p52UcC\& printsec $=$ frontcover $\& d q=$ world + Health + Organization + $+2006 \& \mathrm{hl}=\mathrm{lv} \& \mathrm{ei}=\mathrm{mnBwT}$ 69I4X2sgbGkPX1Bg\&sa $=$ X\&oi $=$ book_result\&ct $=$ result\&resnum $=2$

4. Tassitano, R., Bezerra J., Tenorio M., Colares V., Barros M. \& Hallal P. (2007). Physical activity of Brazilian adolescents: a systematic review. Rev Bras Cineantrop Desempenho Hum 9(1), 55-60. [in Portuguese]

5. Hallal, P., Bertoldi A., Goncalves H. \& Victora C. (2006). Prevalence of sedentary life style and it's factors for 10-12 years old adolescents. Caderno Saúde Pública 22(6), 12771287. [in Portuguese]

6. World Health Organization WHO. (2003, December). Global Strategy on diet, Physical activity and Health Physical activity. Re-trieved December 14, 2009, from WHO database on the World Wide Web: http://www.who.int/dietphysicalactivity/media/en/gsfs_pa.pdf.

7. Paluska, S.A. \& Schwenk T.L. (2000). Physical Activity and Mental Health: Current Concepts. Sports Medicine 29(3), 167-180.

8. Harris, K., Kuramoto L., Schulzer M. \& Retallack J. (2009). Effect of school-based physical activity interventions on body mass index in children: a meta-analysis. CMAJ 180(7), 719-726.
9. Van den Bulk, J. \& Hofman A. (2009). The television-toexercise ratio is a predictor of overweight in adolescents: Results from a prospective cohort study with a two year follow up. Preventive Medicine 48(4), 368-371.

10. Batalha, S., Sousa M., Silveira V., Brandt R. \& Andrade A. (2011, August). Physical activity as a promotion of physical and mental health of adolescents. Retrieved August 5, 2011, from EFDeportes.com on the World Wide Web: http://www. efdeportes.com. [in Portuguese]

11. European Commission. (2010, January). Special Eurobarometer Sport and Physical Activity. Retrieved January 27, 2011, from European Commission database on the World Wide Web: http://ec.europa.eu/public_opinion/archives/ebs /ebs_334_en.pdf

12. Loucaides, C.A., Jago R. \& Charalambous I. (2009, February). Promoting physical activity during school break times: Piloting a simple, low cost intervention. Retrieved February 17, 2011, from Preventive Medicine database on the World Wide Web: http://www.sciencedirect.com/science/article/ pii/S0091743509000711

13. Racette, S.B, Cade W.T. \& Becman L.R. (2010). School-Based Physical Activity and Fitness Promotion. Physical Therapy 90 (9).

14. Špona, A. (2006). Educational process in theory and practice. Rīga: RaKa. [in Latvian]

15. Lieǵeniece, D. (1999). Holistic approach of education. Rīga: RaKa. [in Latvian]

16. Lieǵeniece, D. (1998). Interaction. Let' s learn by cooperating. Rīga: „Mācību grāmata”, SIA. [in Latvian]

17. Piažē, Ž. (2002). Intellectual development of child. Rīga: Pētergailis. [in Latvian]

18. Maslow, A. (1970). Motivation and personality ( $2^{\text {nd }}$ edition). New York: Harper \&Row.

19. Vygotsky, L. (1991). Educational psychology. Moscow: Pedagogika. [in Russian]

20. Kolb, D. (1984). Experiential learning: experience as the source of learning and development. New Jersey: Englewood Cliffs.

21. Andreeva, G. (1980). Social psychology. Moscow: Pedagogika. [in Russian]

22. Mosston, M. \& Ashworth S. (2002). Teaching physical education ( $5^{\text {th }}$ edition.). San Francisco: Benjamin Cummings.

23. Chatoupis, C. (2000). The effects of two teaching styles on physical fitness and perceived athletic competence of fifth grade students. European Journal of Sport Science 3(1).

Submitted: November 30, 2012

Accepted: December 17, 2012 